\title{
EXPERIMENTAL AND NUMERICAL INVESTIGATION ON UPHEAVAL BUCKLING OF FREE-SPAN SUBMARINE PIPELINE
}

\author{
Zhi-hua Chen ${ }^{1}$, Jian-guo Yang ${ }^{1}$ and Zhan-sheng Liu ${ }^{2}, *$ \\ ${ }^{1}$ State Key Laboratory of Hydraulic Engineering Simulation and Safety, Tianjin University, Tianjin, China \\ ${ }^{2}$ Department of Civil Engineering, Beijing University of Technology, Beijing, China \\ *(Corresponding author: E-mail: lzs4216@163.com)
}

\section{A B S T R A C T}

Submarine pipeline is widely used for the transportation of oil and gas in offshore exploration and production. The free span of pipeline is inevitable because of the complex seabed conditions, which may result in the upheaval buckling failure under the service conditions. In this paper, several experimental tests on scale models of submarine pipelines was carried out. The test results show that the length of the free span is closely related with the buckling of the pipeline. The upheaval buckling of pipelines is induced by the high compressive stress due to thermal action and triggered by the initial curvature due to self-weight. Thus, the traditional analysis and design method with effective length method cannot be used. Based on the experimental results, a simple and effective finite element model is developed and verified for parametric study. The numerical simulation results show that the diameter, length of free span and the self-weight of the pipeline will influence the buckling resistance of the pipeline system. The proposed finite element model can be used for the practical design of submarine pipelines.

\section{A R T I C L E H I S T O R Y}

$\begin{array}{ll}\text { Received: } & \text { 24 September } 2018 \\ \text { Revised: } & \text { 02 May } 2019 \\ \text { Accepted: } & \text { 06 May } 2019\end{array}$

\section{K E Y W O R D S}

Submarine pipeline;

Upheaval buckling;

Free span;

Scale model experiment

Numerical simulation

Copyright $\odot 2019$ by The Hong Kong Institute of Steel Construction. All rights reserved.

\section{Introduction}

After nearly a hundred years of exploitation of land-based oil, the storage capacity of oil fields on land has been rapidly reduced. Therefore, the main exploitation of oil has turned to the ocean in recent years. The submarine pipeline system is the common way for oil and gas transportation in the marine oil and gas exploration because of easy construction, low cost and high reliability. Up to the year 2006, the total length of the submarine pipelines in the world had exceeded 175,000 kilometers, which is around 4.4 times of the Earth's equator. The service environment of the submarine pipelines is complex as the internal waves, ocean currents, earthquakes, and many other natural disasters may lead to the failure of the pipelines. In the event of the oil and gas leak in the pipeline, it will cause huge disasters to the marine ecological environment and bring significant losses in the development of the social economy [1]

Generally, the crude oil needs to be transported at high pressure and high temperature because of its high viscosity and high freezing point. With the increase of the pressure and temperature, the stress of the pipeline will be increased. Most importantly, the pipeline may be buckled under high compressive stress and with lack of terrain constraint of the seabed. For this reason, extensive research has been conducted on the failure mechanisms of submarine pipeline system, which can be can be summarized into three approaches. The first is the theoretical research on the buckling of the submarine pipelines. As early as the 1980s, Hobbos et al. [2, 3] developed a buckling critical load calculation formula for the ideal straight pipeline based on the small rotation and line elasticity hypothesis. This formula has been applied to investigate the thermal buckling of semi-infinite long pipeline [4]. Various theoretical buckling models of pipelines under the complex service conditions have been developed in the past three decades [5-8]. The second is the numerical simulation on the buckling of the submarine pipelines. Commercial software such as ABAQUS has been widely used to analyze the buckling of the submarine pipelines $[9,10]$. Because of the inevitable model simplification in both of the theoretical analysis and numerical simulation, the experimental work is necessary to support and verify the theoretical and numerical simulation results. The third is the experimental tests on the buckling of the submarine pipelines. For example, Miles et al. [11] investigated the lateral buckling using an elastic rod and an attenuation formula of the lateral buckling was derived. Feng et al. [12] used the optical fiber sensor to measure the strain distributions of the submarine pipeline during the pre-buckling and post-buckling responses. The reliability of the optical fiber measurement method in this application has been verified. In general, the experimental study on the submarine pipelines were based on the scale model but not the full-scale model. The section dimensions, loading modes, test objects and other factors may affect the test results. Thus, only the experimental work on the buckling of the submarine pipelines is insufficient.

From the above, a simple and effective analysis and design approach for submarine pipelines is still limited. The high temperature in the pipelines not only induce thermal stress but also change the material properties. Therefore, the conventional design method based on the effective length method cannot be used. Hence, the use of both experimental and numerical tests is an effective and reliable method to investigate the actual behaviors of submarine pipelines. It is noted that the pipelines with free spans are very common in the submarine structures and upheaval buckling failures may be induced [13]. In this paper, the experiment tests using scale model has been were conducted. Further, an numerical simulation model is proposed and verified by the experimental test results. Finally, the factors related to the upheaval buckling of the pipelines with free spans are discussed and some recommendations are provided.

\section{Experimental test of scale model}

\subsection{Scale Model and Test Setup}

Submarine pipelines are commonly made of X65 or the higher grade steels in the practical engineering application. Compared to the aluminum alloy, the steel possesses the larger self-weight, higher elastic modulus, and lower thermal conductivity. If the steel specimen is adopted in the experimental test, the buckling failure mode can not be observed due to limited capacity of the facilities. Therefore, the pipeline specimen made of 6061T6 aluminum alloy was tested instead of steel pipeline in this paper [15]. The material properties of aluminum $6061 \mathrm{~T} 6$ are shown in Table 1 . The dimensions of the aluminum pipeline specimen are given as follows: the diameter is $70 \mathrm{~mm}$, the wall thickness is $2 \mathrm{~mm}$, and the length is $9000 \mathrm{~mm}$.

Table 1

The material properties of $6061 \mathrm{~T} 6$ aluminum

\begin{tabular}{ccccccc}
\hline Average density (kg/m3) & Melting point ( $\left.{ }^{\circ} \mathrm{C}\right)$ & $\begin{array}{c}\text { Linear expansion } \\
\text { coefficient }\left({ }^{\circ} \mathrm{C}-1\right)\end{array}$ & Specific heat (cal/g) & $\begin{array}{c}\text { Thermal conductivity } \\
\left(\mathrm{cal} \mathrm{cm} \mathrm{s}{ }^{\circ} \mathrm{C}\right)\end{array}$ & Resistivity ( $\mu \Omega$ cm) & Elastic modulus (GPa) \\
\hline 2700 & 658 & $24 \times 10^{-6}$ & 0.225 & 0.52 & 2.84 & 68.5 \\
\hline
\end{tabular}


The illustration of the experimental setup is shown in Fig. 1, which includes the oil heating pump, the seabed simulated by sand, and the fixed end. The temperature load was applied to the pipeline specimen by the oil heating pump. The oil flow is heated up from the room temperature while the temperature rising process was paused every $10{ }^{\circ} \mathrm{C}$. When the deformation of the specimen was stable in the pause step, the strain, displacement, and other parameters were recorded. The temperature rising process was continued until the buckling failure was observed in the aluminum pipeline.

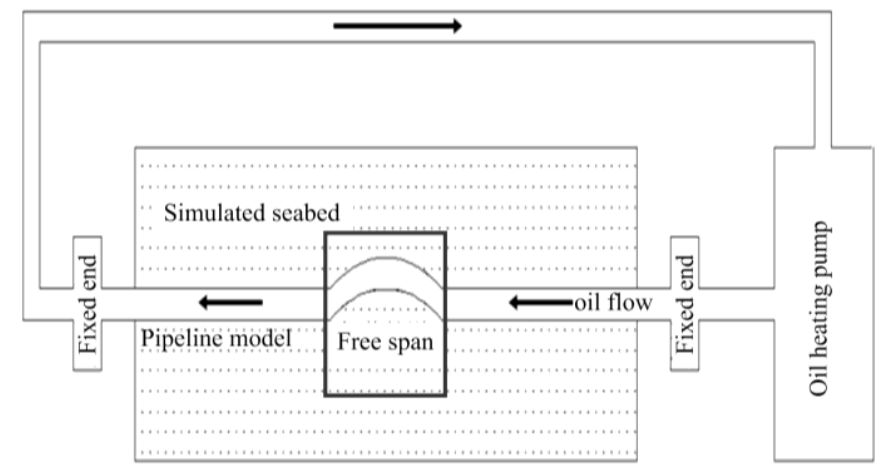

Fig. 1 The illustration of the experimental setup

The two ends of the pipeline specimen should be in a line and fixed at the edge, which can minimize the bending moment induced during the temperature loading process. Since the simulated seabed was made of fine sand, the depression would be formed on the simulated seabed by the sinking of the pipeline. In order to remove this influence, the sand on both sides of the lower part of the pipeline model was removed. The angle bars were added at the ends of the free span to simulate the hard contact, which can prevent the changes of boundary conditions because of the slippage of the sand in the deformation process of the pipeline model. The main purpose of this paper is to investigate the upheaval buckling. Thus, the articulated connection was selected between the ends of the pipeline model and the fixed ends. Two steel bars were welded at both sides of the pipeline model to limit the lateral displacement of the pipeline model. Fig. 2(a) shows the overall setup of experimental setup while Fig. 2(b) shows the connection between the end of the specimen and the fixed end of seabed.
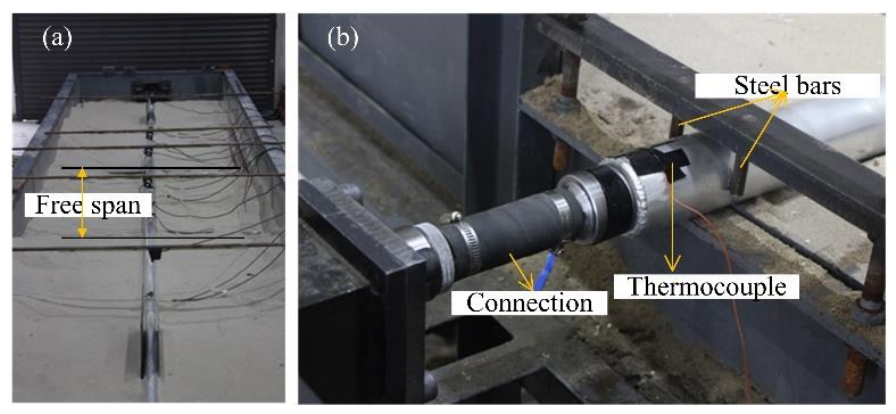

Fig. 2 Experimental test photos: (a) Overall setup; (b) End connection details

As the temperatures, strains, displacements at the different locations of the specimen were different, five displacement measurement points were arranged along the pipeline, as seen in Fig. 3. The range of the displacement transduser used in this experimental test was $500 \mathrm{~mm}$ with the sensitivity of $0.5 \mathrm{~mm}$. The high-temperature strain gauges were adhered on the middle point (point 3 in Fig. 3) to measure both the axial strain and the bending strain.

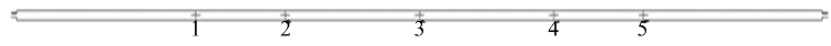

Fig. 3 The arrangement of five displacement measurement points

The high compressive stress due to temperature will lead to the buckling of the pipeline specimen. Thus, five temperature measurement points were arranged along the pipeline as indicated in Fig. 4. Point 1 was located on the oil inlet and point 5 was located on the oil outlet. The thermocouples with the temperature acquisition frequency of $1 \mathrm{time} / \mathrm{s}$ were used to measure the temperature.

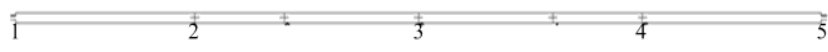

Fig. 4 The arrangement of five temperature measurement points

Three groups of specimens have been tesed to study the influence of free span length, which are listed in Table 2. The mean values of the test results for each group were taken as the reliable results. The curves of the temperature loading history are plotted in Fig. 5. T1 to T5 represent the temperatures of five temperature measurement points. It can be seen that the temperature has a certain loss along the oil flow path, which is the same as the observations in practical engineering. Moreover, as the length of the free span increases, the temperature loss decreases.

Table 2

The specimens in experimental test

\begin{tabular}{clll}
\hline Group & 1 & 2 & 3 \\
\hline Length of free span (m) & 2 & 3 & 4 \\
Number of pipeline specimen & 3 & 3 & 3 \\
\hline
\end{tabular}

(a)

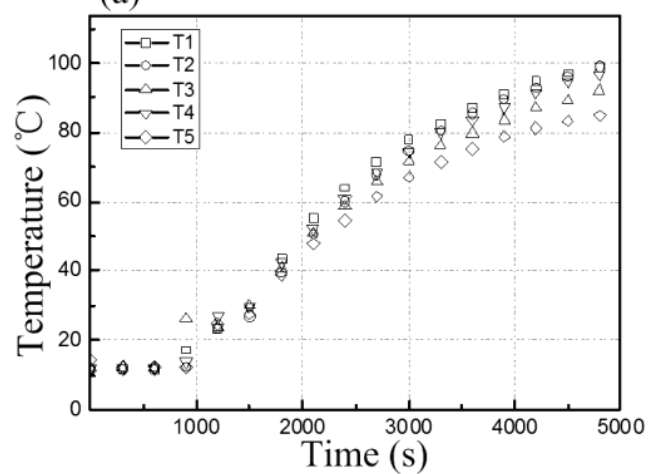

(b)

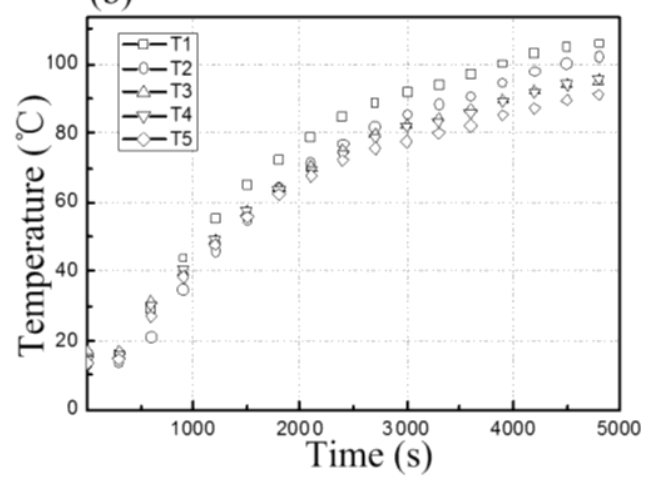

(c)

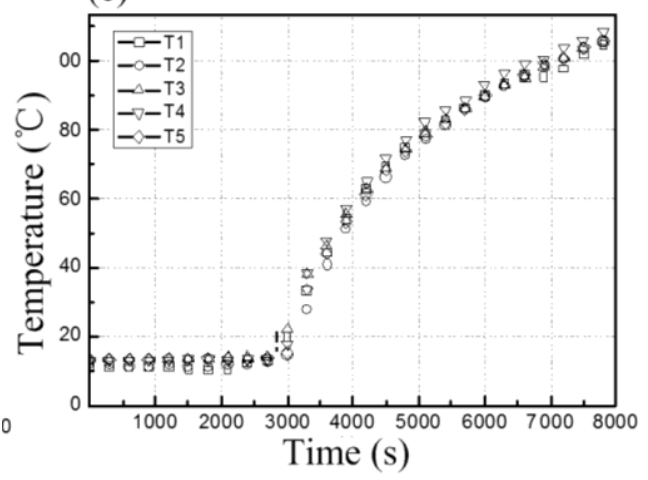

Fig. 5 The curves of the temperature loading history with different length of free span: (a) Length $=2 \mathrm{~m}$; (b) Length $=3 \mathrm{~m}$; (c) Length $=4 \mathrm{~m}$

\subsection{Experimental results and discussion}

As shown in Fig. 6(a), the self-weight of the free span induces the initial geometrical imperfection of the pipeline specimen, which will lead to upheaval buckling failure of the pipeline under compression. In the process of the oil temperature increase, due to the axial constraints at both ends and lack of lateral constrains at the free span, the pipeline model was displaced vertically and 
finally failed due to the buckling. Also, because of the constraints of the steel angles, the pipeline specimen exhibited a wave-shaped buckling mode, seen in Fig. 6(b).
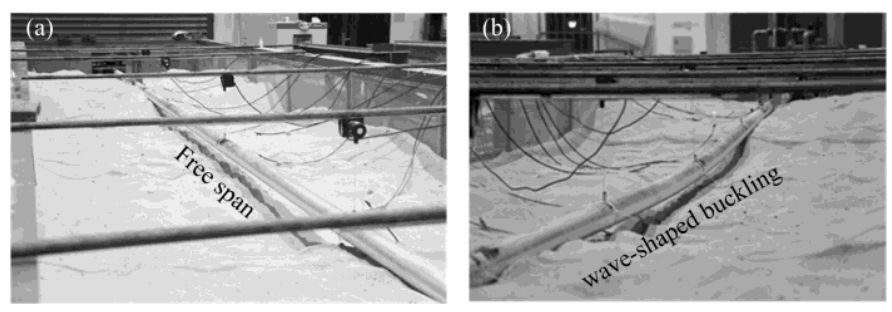

Fig. 6 Typical specimen in test: (a) Initial state; (b). Buckling failure mode

The mean values of the vertical displacement on the middle point of the pipeline model of each specimen group are plotted in Fig. 7. The maximum vertical displacement of the pipeline model with $2 \mathrm{~m}$ free span was only $8 \mathrm{~mm}$ and the buckling phenomenon seems not obvious. For the pipeline model with $3 \mathrm{~m}$ free span, the increase of the vertical displacement was linear in the loading process and the increase rate decreased after the buckling occured. When the length of the free span was $4 \mathrm{~m}$, the increase rate of the vertical displacement was higher and the maximum vertical displacement was up to $85 \mathrm{~mm}$. The buckling rate is higher and the critical temperature is the lowest. The main reason for the above-mentioned phenomenon is the use of the steel angle at the ends of the free span which provided sufficiently rigid boundary. When the length of the free span is small, the thermal displacement of the pipeline model is small due to the restraint of the steel angle. When the free span is longer, the initial geometrical imperfection induced by the self-weight of the free span becomes important and will trigger the buckling. Although the steel angle provides rigid boundary and the pipeline specimen is almost straight before appling thermal load, the initial curvature of the pipeline induced by the gravity load results in the clear upheaval buckling failure.

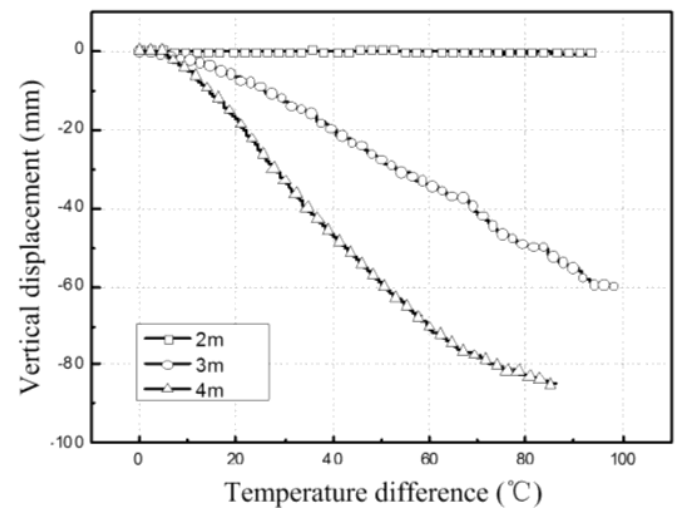

Fig. 7 Temperature versus vertical displacement curves from test

The axial force of the middle point of the pipeline model was calculated by the formula of $\mathrm{F}=\varepsilon \mathrm{A}$, in which $\mathrm{A}$ is the cross-sectional area of the pipeline while $\varepsilon$ is the axial strain measured by the strain gauge. The mean value of the axial force of each specimen group was calculated. Fig. 8(a) shows the relationship between the axial force and the temperature difference. For the pipeline with $2 \mathrm{~m}$ free span, because the axial constraint of the ends had a certain gap, the deformation of the middle point of the pipeline model was rapid and the axial force increased fast before the temperature difference of $20^{\circ} \mathrm{C}$. When the gap was offset, the axial force changed slowly between the temperature differences from $20^{\circ} \mathrm{C}$ to $60^{\circ} \mathrm{C}$. When the temperature is higher than $60^{\circ} \mathrm{C}$, the axial force continuously increased and induced buckling failure after $90^{\circ} \mathrm{C}$. For the pipeline with a free span of $3 \mathrm{~m}$, the tensile axial force occurred at the initial stage of the temperature loading, which tightened the pipeline model and fixed ends. With the increase of temperature, the tensile axial force was changed to compressive axial force. When the axial force was increased up to $230 \mathrm{kN}$ at the temperature difference of $90^{\circ} \mathrm{C}$, the pipeline was buckled. For the specimens with free span of $4 \mathrm{~m}$, the axial force changed with a fluctuation. The axial force increased linearly after the temperature difference of $20^{\circ} \mathrm{C}$. Fig. $8(\mathrm{~b})$ is the relationship between the axial force and the vertical displacement of the middle point of the pipeline model. For the pipeline model with $2 \mathrm{~m}$ free span, because of the short length and the large diameter of the pipeline model, the small initial curvature at free span resulted in the small displacement which was near to zero.
For the pipeline model with $3 \mathrm{~m}$ free span, the specimen was buckled when the vertical displacement reached $40 \mathrm{~mm}$ with the axial force of $150 \mathrm{kN}$. The axial force increased slowly in post-buckling range, but the vertical displacement continuously increased. When the free span of the specimen was $4 \mathrm{~m}$, the pipeline model was buckled when the vertical displacement reached $10 \mathrm{~mm}$ with the axial force of $75 \mathrm{kN}$.
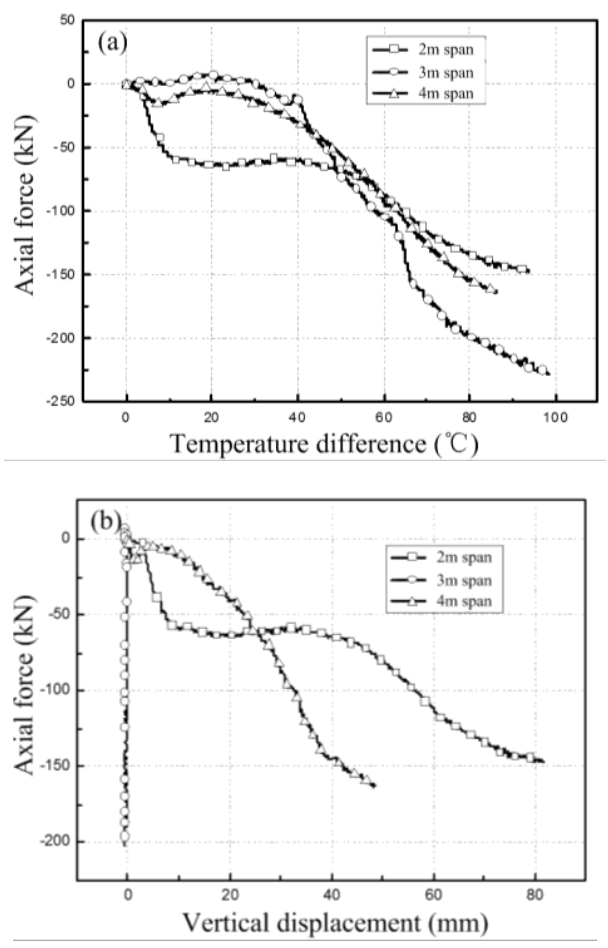

Fig. 8 Axial forces from test: (a) axial force vs. temperature difference; (b)axial force vs. vertical displacement

\section{Numerical simulation study}

\subsection{Numerical simulation model}

In this paper, the commercial software ABAQUS was used to establish the finite element model. The specific modeling and analysis process are described as follows:

(1) The element types used in the model was based on the structural behaviors the objects [16]. The submarine pipeline is a typical slender structure, in which the dimension in one direction is much larger than that in the other two directions. Therefore, the beam element (B21) was selected to simulate the response of the pipeline. For each model, 300 bean elements are used to model the pipeline. The seabed was simulated by the rigid contact surface (R2D2). The contact model between the pipeline model and the seabed was set as the hard contact. For each model, 300 rigid elements are used to model the seabed. And the frictional behavior was represented by the Coulomb friction model.

(2) The length of the pipeline model was evaluated. Because of the obvious localized feature of the submarine pipeline buckling, the buckling behavior generally affects a small part of the total length of the pipeline [14]. Therefore, it is not necessary to establish the finite element model with the total length of the pipeline. In this paper, the length of the pipeline model was selected as 50 times the length of the free span.

(3) The constraints at both ends of the pipeline model were determined. The submarine pipeline would have an elongation tendency under the action of the internal temperature. As the frictional force of the seabed soil accumulates in the axial direction, the pipe anchoring section is finally formed. Because two ends of the anchoring section have no axial displacement, the constraints at both ends of the pipeline model were determined as articulated connection.

(4) The loading type was determined. The main reason for the pipeline buckling is the axial force generated by the expansion effect. Therefore, the pressure induced by the increase of temperature was the loading type in this paper.

(5) The analysis steps and method were determined. The simulation work was mainly divided into two load steps. Firstly, the self-weight was applied on the model, which is a general static analysis step. Second, a temperature action was applied to the pipeline, involving a time-history of thermal analysis. 


\subsection{Verification of the numerical model}

Based on the parameters of the scale models in experimental test, the numerical simulation models were established according to section 3.2 and then they were verified by the test results presented in section 2.2. Fig. 9 shows the comparison of axial force-temperature curves obtained by experimental and numerical simulation. It can be seen from Fig. 9 that the basic trend of the curves from simulation and experiment are the same. The critical buckling force derived by the numerical simulation is slightly smaller than that observed from the experimental test. The reason may be due to the use of fully restrained boundary conditions in numerical simulation while the support conditions of the pipeline specimens in the experimental test were semi-rigid. In general, the numerial results shows in good agreement with the test and therefore the proposed FE model will be used for further parametric study on the responses of pipelines under more conditions.

(a)

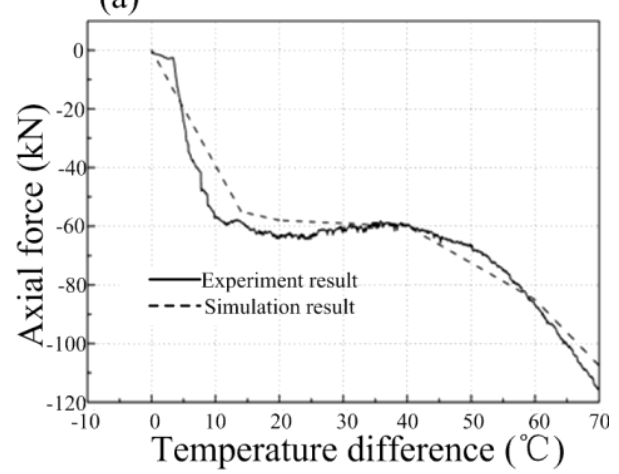

(b)

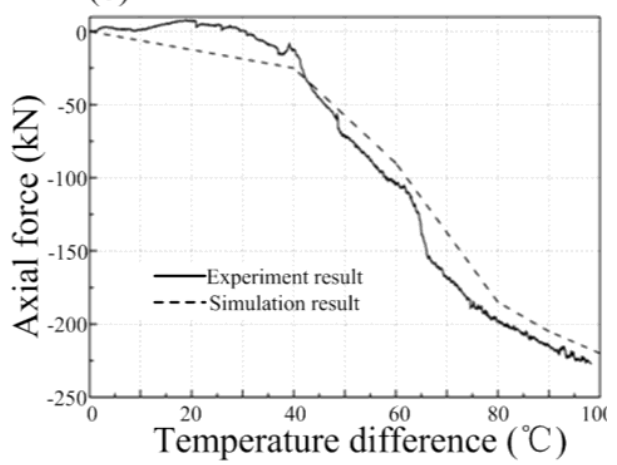

(c)

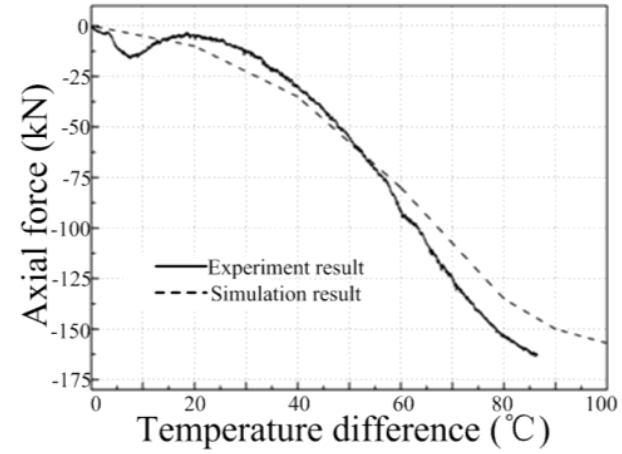

Fig. 9 The axial force-temperature curves with different length of free span: (a) Length = $2 \mathrm{~m}$; (b) Length $=3 \mathrm{~m}$; (c) Length $=4 \mathrm{~m}$

\section{Parametric study}

Unlike the specimens tested in section 2 which were made of aluminum 6061T6, the material of the pipeline in FE model is steel to represent the actual conditions in practical engineering. The elastic modulus is $207 \mathrm{GPa}$ while the linear expansion coefficient is $11 \times 10-6$. The main parameters of the pipelines in numerical simulation study are listed in Table 3.

Table 3

The main parameters of pipelines in numerical simulation study

\begin{tabular}{cc}
\hline Diameter $(\mathrm{mm})$ & $254,273,323,355,381$ \\
Wall thickness $(\mathrm{mm})$ & 12 \\
Length of the free span $(\mathrm{m})$ & $20,24,28,32,36,40$ \\
Self-weight $(\mathrm{N} / \mathrm{mm})$ & $0.6,0.8,1.0,1.2,1.4$ \\
\hline
\end{tabular}

The first step was the static analysis of the pipeline subjected to self-weight only. The second step is thermal analysis by increasing the temperature until the failure is observed.

Fig. 10 shows the displacement and the von Mises stress contours of the pipeline model under $100^{\circ} \mathrm{C}$ with the parameters of $254 \mathrm{~mm}$ diameter, $12 \mathrm{~mm}$ wall thickness, $0.6 \mathrm{~N} / \mathrm{mm}$ self-weight, and $20 \mathrm{~m}$ free span. Because the upheaval buckling is a local behavior of the pipeline model, only a part of the pipeline model including the buckling failure is shown in Fig. 10. Obviously, there is no vertical displacement of the section of the pipeline model away from the free span. Because the self-weight of the free span results in the deflection of the free span and the warping of two sides of the free span, the free span acts as an initial vertical defect in the loading process which leads to the upheaval buckling of the pipeline model. The buckling shape of the pipeline model includes two peaks and one trough. The stress at the peak and the trough are larger. The maximum vertical displacement of the trough is smaller than that of the peak.

(a)

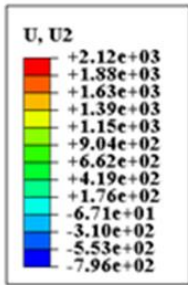

(b)

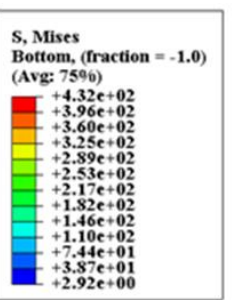

Fig. 10 Typical specimen in test: (a) Initial state; (b). Buckling failure mode 
Fig. 11 shows the whole process of the vertical buckling of the pipeline model with the parameters of $381 \mathrm{~mm}$ diameter, $12 \mathrm{~mm}$ wall thickness, 1.0 $\mathrm{N} / \mathrm{mm}$ self-weight, and $32 \mathrm{~m}$ free span. As shown in Fig. 11(a), the structural self-weight induced the small initial vertical displacement at the free span and the small warping of two sides of the free span before the increase of temperature. In the early stage of buckling development, the vertical displacement of the free span is always greater than that of two-sided warping section. The influence range of the buckling section appears as a symmetrically extended state on both sides. When the temperature rises to the buckling critical value, the vertical displacement of the buckling section develops rapidly. The vertical displacement of two-sided warping section gradually exceeds that of the free span, which becomes the main buckling section. The increase of the buckling displacement of the free span slows down. Fig. 11(b) shows the development of the combined stress. Obviously, the stress development of the buckling also shows a symmetric distribution and gradually expands outward as the temperature rises. Before the buckling occurs, the stress level of the pipeline model is low. There are two compressive stress peaks at two sides of the free span and one tensile stress peak in the middle of the free span. After the buckling occurs, the stress shows a waveform distribution. There are three tensile stress peaks and two compressive stress peaks, in which the tensile stress peaks on both sides appear near the initial point of bending of the pipeline model. The tensile stress peak in the middle point of the pipeline model corresponds to the location of the maximum vertical displacement of the free span. Two compressive stress troughs occur on both sides in Fig. 11(b). It is worth noting that after the buckling occurs, the individual stress peaks propagate rapidly symmetrically along both sides of the pipeline model.
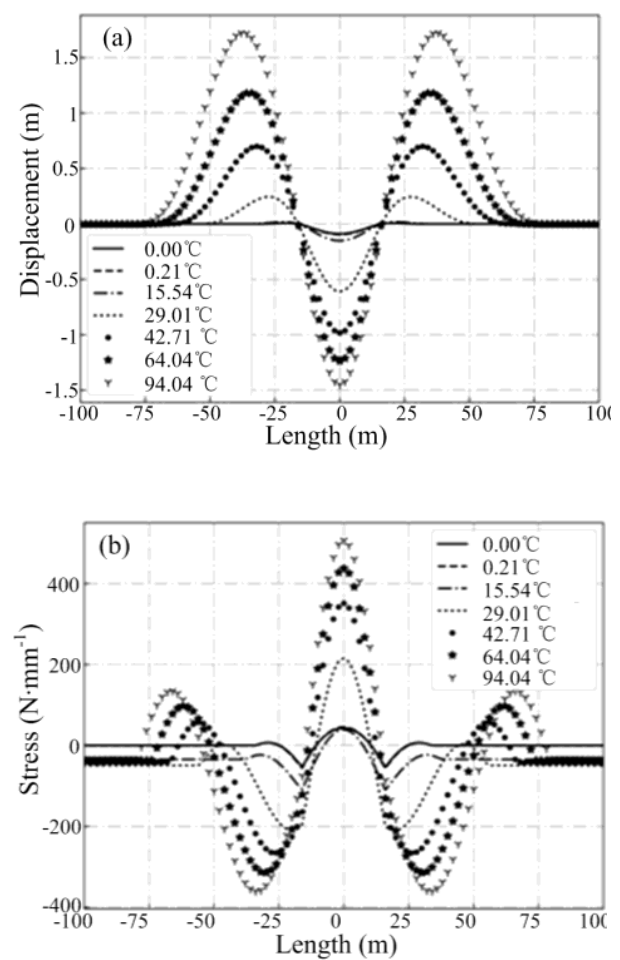

Fig. 11 Simulation results along the pipeline: (a)Displacement distribution; (b) Stress distribution

The axial force and the vertical displacement of the middle point of the pipeline model were used to investigate the influence of the free span length, the diameter, and the self-weight on the buckling mode. Fig. 12 shows the influence of the length of the free span on the buckling of the pipeline model. In this simulation test groups, the diameter is $381 \mathrm{~mm}$ and the thickness of the wall is $12 \mathrm{~mm}$. As shown in Fig. 12(a), there are two main development modes of buckling displacement: when the length of the free span is small, the vertical displacement of the pipeline model is small before the buckling; while after the buckling occurs, the displacement of the pipeline model develops rapidly to reach a new equilibrium state. Then the displacement continues to increase slowly with the increase of temperature. Meanwhile, there is a certain dynamic effect during the temperature rise process, which has the characteristics of jumping buckling. When the length of the free span is longer, the initial deflection of the pipeline model is larger with slow development of displacement. Fig. 12(b) shows the development of the axial force of the middle point of the pipeline model. Obviously, the critical bending axial force gradually decreases as the length of the free span increase. The main development modes of buckling axial force can be classified into two categories: when the length of the free span is small, there is a significant critical buckling axial force. The axial force decreases rapidly after the critical buckling axial force. When the length of the free span is longer, there is no obvious critical buckling axial force and the axial force change slowly with the temperature rise.
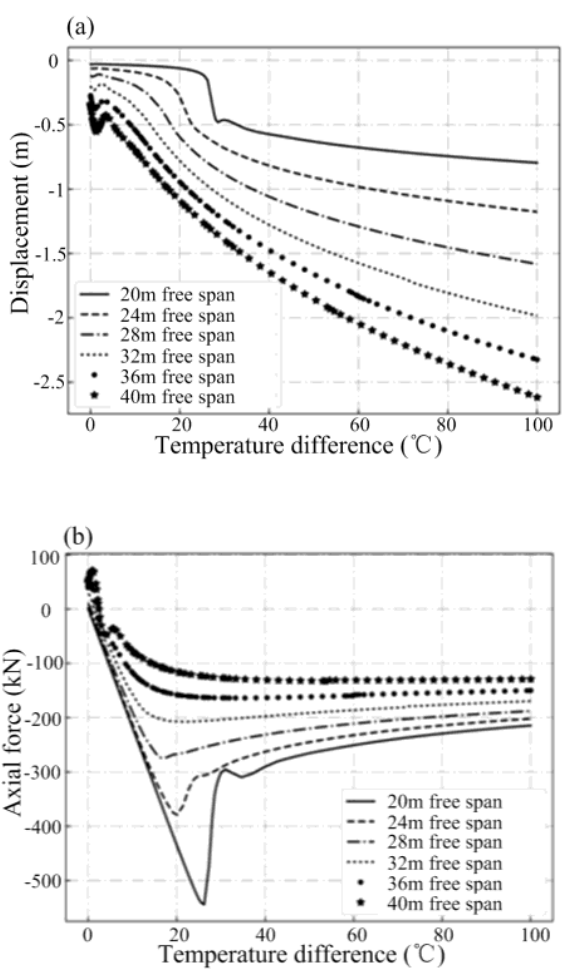

Fig. 12 Displacements and axial forces related to length of free span: (a) Displacementtemperature curves; (b) Axial force-temperature curves

Fig. 13(a) is the relationship between vertical displacement of the middle point of the pipeline and the temperature difference under different diameters; while Fig. 13(b) is the relationship between axial force of the middle point of the pipeline and the temperature difference under different diameters. In this simulation groups, the length of the free span is $32 \mathrm{~m}$ and the thickness of the wall is $12 \mathrm{~mm}$. The different diameters also would result in two vertical buckling models. When the diameter is small, the buckling displacement develops gently and there is no obvious critical buckling force. After the critical axial force, the axial force of buckling section drops gently. When the diameter of the pipeline is larger, there is a sudden change in the buckling displacement, and there is a significant critical buckling axial force. After breaking the critical value, the axial force of the buckling section decreases rapidly, accompanied with a dynamic effect.

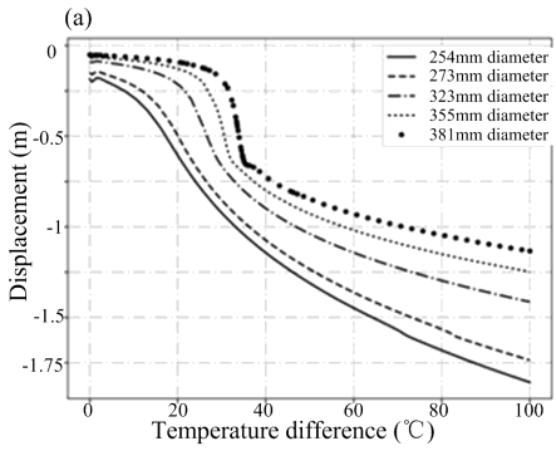




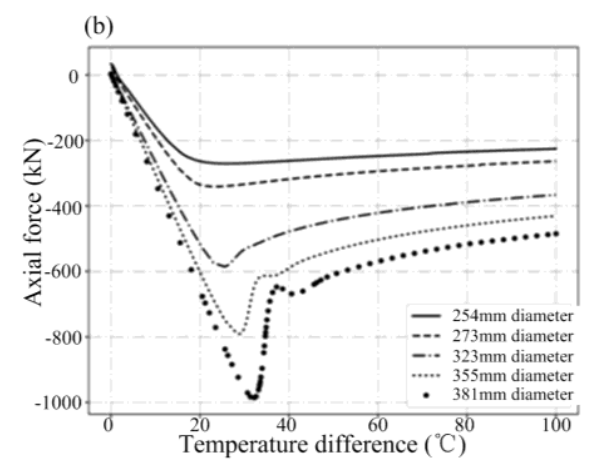

Fig. 13 Displacements and axial forces related to diameter of pipeline: (a) Displacementtemperature curves; (b) Axial force-temperature curves

Fig. 14 shows the effect of the self-weight on the buckling modes of the pipeline model. In this simulation groups, the diameter is $381 \mathrm{~mm}$, the length of the free span is $32 \mathrm{~m}$ and the thickness of the wall is $12 \mathrm{~mm}$. Compared to the influence of the length of the free span and the diameter, the effect of the selfweight on the buckling of the pipeline model is small. As the self-weight of the pipeline model increases, the final post-buckling displacement of the pipeline model increases, the critical buckling temperature corresponding to the buckling of the pipeline model also increases, and the post-buckling axial force increases.

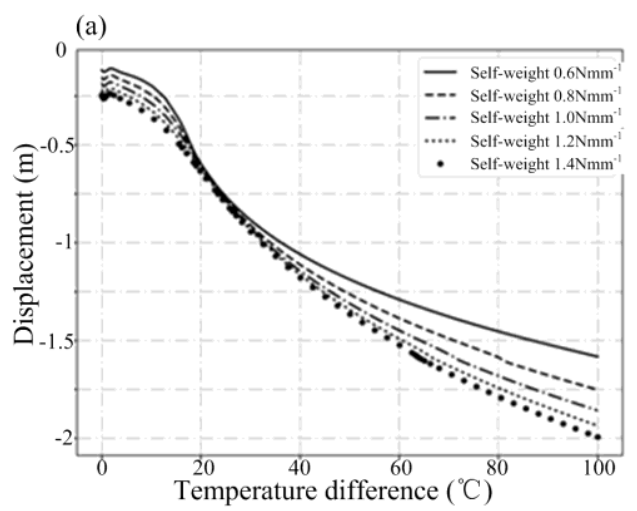

(b)

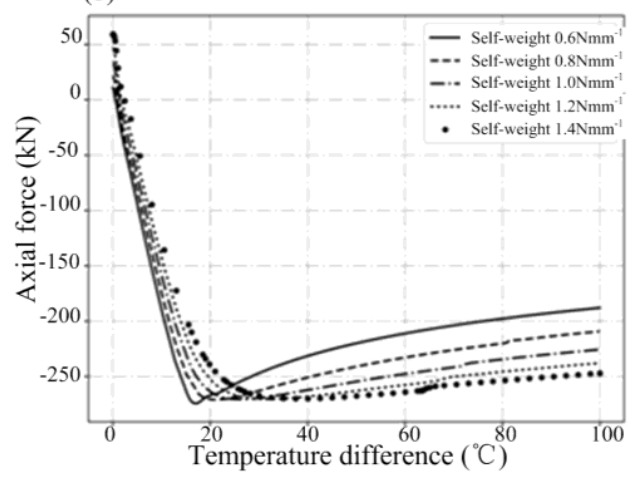

Fig. 24 Displacements and axial forces related to self-weight of pipeline: (a) Displacement-temperature curves; (b) Axial force-temperature curves

\section{Conclusions}

Submarine pipelines have been extensively used in the transportation of oil and gas. However, the pipeline is prone to upheaval buckling failure under the service conditions. There is still lack of reliable design method for the submarine pipelines as the conventional design method is mainly based on effective length method with the assumption of initially undeformed configuration. In this paper, several experimental tests on scale models of submarine pipelines have been conducted and a simple and effective finite element (FE) model is proposed and verified by the test results. Further, the proposed FE model is used for parametric study. The influence of free-span length, diameter and wall thickness of pipeline has been investigated.

In summary, the following conclusions can be drawn from this paper.

1. The upheaval buckling of pipelines is induced by the high compressive stress due to thermal action and triggered by the initial curvature due to selfweight.

2. A simple and effective finite element model is developed and verified by the test results. Parametric study has been conducted to investigate the influence of several factors such as free-span length, the diameter and wall thickness of the pipeline.

3. The simulation results show that the pipeline has two vertical buckling modes. When the diameter of the pipe is large or the length of the free span is small, the jump buckling of the pipe will occur, which should be avoided in actual engineering. When the pipe diameter is small or the free span is large, the buckling process of the pipe is relatively gentle and should be carefully evaluated to ensure the safety of the pipe in the buckling state.

4. The length of the free span and the diameter of the pipe are the two most important factors affecting upheaval buckling behavior. As the diameter increases and the length of the free span decreases, the critical bending crankshaft force of the pipe increases.

5. The proposed FE model is simple and effective for practical design of submarine pipelines.

\section{Acknowledgement}

The authors are grateful for the support provided by the National Basic Research Program of China under Grant No. 2014CB046801.

\section{References}

[1] Zhu Y., Qian X., Liu Z., et al., "Analysis and assessment of the Qingdao crude oil vapo explosion accident: lessons learnt", Journal of Loss Prevention in the Process Industries, 33, 289-303, 2015

[2] Hobbs R.E., "In-service buckling of heated pipelines", Journal of Transportation Engineering, ASCE, 110(2), 175-189, 1984.

[3] Hobbs R.E., "Pipeline buckling caused by axial loads", Journal of Constructional Steel Research, 1(2), 2-10, 1981.

[4] Hobbs R.E. and Liang F., "Thermal buckling of pipelines closed to restraints", International Conference on Offshore Mechanics and Arctic Engineering, 1(5), 121-127, 1989.

[5] Miles D.J. and Calladine C.R., "Lateral thermal buckling of pipelines on the sea bed", Journal of applied mechanics, 66(4), 891-897, 1999.

[6] Bokaian A., "Thermal expansion of pipe-in-pipe systems", Marine Structure, 1(17), 475-500, 2004.

[7] Hong Z., Liu R., Liu W., et al., "Study on lateral buckling characteristics of a submarine pipeline with a single arch symmetric initial imperfection", Ocean engineering, 108(21-32), 2015.

[8] Wang Y., Zhang X., Zhao Y., et al., "Perturbation analysis for upheaval buckling of imperfect buried pipelines based on nonlinear pipe-soil interaction", Ocean Engineering, 132(92-100), 2017.

[9] Peek R. and Yun H., "Flotation to trigger lateral buckles in pipelines on a flat seabed", Journal of Engineering Mechanics, 133(4), 442-451, 2007.

[10] Liu, R., Xiong, H., Wu, X., et al., "Numerical studies on global buckling of subsea pipelines", Ocean Engineering, 78(1), 62-72, 2014.

[11] Miles D.J. and Calladine C.R., "Lateral thermal buckling of pipelines on the sea bed", Journal of applied mechanics, 66(4), 891-897, 1999.

[12] Feng X., Wu W., Li X., et al., "Experimental investigations on detecting lateral buckling for subsea pipelines with distributed fiber optic sensors", Smart Structures \& Systems, 2(15), 245-258, 2015.

[13] Furnes G.K. and Berntsen J., "On the response of a free span pipeline subjected to ocean currents", Ocean engineering, 30(12), 1553-1577, 2003.

[14] Standard O., "Submarine Pipeline Systems. DNV-OSF101", DNV, 2000.

[15] Yu J.X., An S.Y., Sun Z., et al. Envisage and analysis of sea trial on deep-water pipeline's resistance to external pressure, Ocean Engineering, 2018.

[16] Yu J.X., Li Z.B., Du Z.F., et al. Theoretical calculation method of the nonlinear buckling of deepsea pipes, The Ocean Engineering, 2013 